\title{
0 morrer para graduandos em Enfermagem: a contribuição da Psicologia
}

\author{
The die for undergraduates in nursing: the contribution of \\ psychology
}

\section{El morir para los estudiantes de enfermería: la contribución de la psicología}

Recebido:28/05/2013

Aprovado: $16 / 10 / 2013$

\author{
Gheysa Alves Mendonça ${ }^{1}$ \\ Valtuir Duarte Souza Júnior ${ }^{2}$ \\ Nivea Lourenço Santos Correio ${ }^{3}$ \\ Álvaro Silva Santos 4
}

A morte, para a Enfermagem, representa uma experiência calcada no saber científico com influência de determinações psicossociais, requerendo, assim, subsídios de natureza psicológica. 0 objetivo deste estudo é investigar a percepção de estudantes de Enfermagem frente ao processo de morrer e à morte em Unidade de Terapia Intensiva (UTI), com análise de contribuição da Psicologia. Trata-se de uma pesquisa qualitativa com utilização de entrevista individual semiestruturada e método de Adaptação da Análise de Conteúdo. Os dados foram divididos em duas categorias: concepção prévia e contextualização da situação. A falta de preparo teóricoprática e de apoio psicológico para lidar com a morte mostrou-se evidente. A Psicologia deve proporcionar subsídios para o exercício da Enfermagem por meio de ações para compreensão e enfrentamento do processo de morrer e da morte.

Descritores: Psicologia; Enfermagem; Atitude frente à morte.

Death to the nursing represents an experience using the scientific knowledge with the influence of psychosocial determinations, requiring subsidies of psychological nature. The objective of this study is to investigate the perception of nursing students in front of the process of dying and death in intensive care unit (ICU), with contribution analysis of Psychology. Qualitative research with use of individual interview semi-structured and method of adjustment of content Analysis. The data was divided into two categories: prior design and contextualization of the situation. The lack of theoretical preparation and practice of psychological support for dealing with the death was evident. Psychology should provide subsidies for the practice of Nursing through actions for understanding, confronting the process of dying and death.

Descriptors: Psychology; Nursing; Attitude to death.

La muerte para la enfermería es una experiencia basada en el conocimiento científico y la influencia de las determinaciones psicosociales, por lo que requiere subsidios psicológicos. El objetivo de este estudio es investigar la percepción de estudiantes de Enfermería sobre el proceso de morir y de la muerte en la Unidad de Cuidados Intensivos (UCI), con el análisis de la contribución de la Psicología. Este es un estudio cualitativo con entrevistas individuales semi-estructuradas y método de adaptación de Análisis de Contenido. Los datos se dividierón en dos categorías: contextualización anterior y concepción de la situación. La falta de preparación teórica práctica y de apoyo psicológico para hacer frente a la muerte era evidente. La Psicología debe proporcionar subsidios para la práctica de Enfermería a través de acciones para comprender y hacer frente al proceso de morir y de la muerte.

Descriptores: Psicología; Enfermería; Actitud frente a la muerte.

1. Psicóloga. Secretaria Municipal de Saúde de Uberaba. Email: gheysamend@hotmail.com

2. Enfermeiro. Especialista em UTI com ênfase em Urgência e Emergência. Mestrando em Enfermagem pela Escola de Enfermagem de Ribeirão Preto - EERP. Universidade de São Paulo- USP. Email: valtuirduarte@gmail.com

3. Psicóloga. Email: nivea.mendes@gmail.com

4. Enfermeiro. Doutor em Ciências Sociais. Professor Adjunto da Universidade Federal do Triângulo Mineiro. Email: alvaroenf@hotmail.com 


\section{INTRODUÇÃO}

T uma visão biológica, a morte é um fenômeno natural, parte do processo de desenvolvimento dos seres, possuindo aspectos subjetivos e simbólicos envolvidos, com influência sociocultural, proporcionando variáveis condutas dos indivíduos diante desse fato ${ }^{1}$. A morte apresenta-se sempre envolvida por misticismos e por diversas cerimônias que variam conforme a época e o perfil da sociedade. $\mathrm{Na}$ Antiguidade, as tribos realizavam rituais fúnebres. Essas condutas diante da morte diminuíam suas consequências sobre os indivíduos, aplacando neles o seu temor ${ }^{2}$.

Na Idade Média, a sociedade europeia via a morte com naturalidade e como parte do cotidiano familiar. Os cemitérios eram construídos nos centros das cidades, dominados pela igreja católica, e os mortos eram enterrados de acordo com a representação social do indivíduo: os mais importantes eram enterrados dentro das igrejas, os outros em terrenos ao lado, e os considerados sem dignidade eram jogados em valas abertas, por onde as pessoas transitavam sem se importar com a situação. Em algumas sociedades, na ocorrência da morte, eram realizados eventos como festas macabras, em que ocorria a realização de banquetes e eram servidas bebidas para os convidados ${ }^{3}$.

Com o decorrer dos anos, a morte saiu do ambiente familiar e migrou para o ambiente hospitalar, passando de um processo vivido por toda a família (incluindo também as crianças) para o hospital, local considerado como ambiente isolado, frio e doloroso. Nesse contexto, podem-se identificar vários fatores relacionados que interagem influenciando na representação social que a morte tem na atualidade. Quando a morte era vivenciada por toda a família no contexto doméstico, era vista com menos temor, sendo considerada como parte natural do processo da vida, e os familiares e o próprio moribundo construíam a aceitação da morte no dia a dia, na realização dos cuidados, na qual todos se sentiam mais confortados e revelavam aceitação das condições de saúde do indivíduo e suas consequências ${ }^{4}$.

Vivencia-se, hoje, uma sociedade negadora da morte. 0 doente passa a sofrer de maneira solitária suas angústias, longe do meio em que viveu, dentro de um hospital cercado por profissionais de saúde e sendo submetido a várias técnicas e procedimentos dolorosos referentes ao tratamento. Diante dessa condição, o morrer passa a ser cada vez mais temido e difícil de ser aceito.

Para os profissionais de saúde, a elaboração do morrer também não é diferente, pois, além de ter que conviver com sua própria finitude e a de seus entes queridos, também têm que se fortalecer para a perda do paciente e se posicionar dando apoio aos familiares deste, que acompanham esse processo. Diante desse fato, o profissional pode passar a indagar a própria competência profissional, sentindo culpa e frustração pela morte do paciente sob seus cuidados, não a compreendendo como um processo natural da vida, e sim como incapacidade, pois em sua formação foi ensinado a salvar vidas e não a perde-las ${ }^{2}$.

Os trabalhadores da área da saúde, principalmente os médicos e enfermeiros, durante sua graduação, aprendem mais como cuidar do paciente, como mantê-lo vivo, como curá-lo e não como cuidar daquele que está morrendo. Os profissionais de Enfermagem apresentam dificuldades em vivenciar a perda dos pacientes sob seus cuidados, principalmente aqueles que trabalham em setores onde os pacientes se encontram em estado mais grave (UTI adulta, neonatal ou pediátrica; setor de oncologia, pronto atendimento e outros), esperando que a morte seja uma realidade inseparável do cotidiano de trabalho ${ }^{5}$.

Dentre os fatores que prejudicam a qualidade de vida dos profissionais de Enfermagem, por propiciarem um clima tenso de atuação, estão a constante exposição à dor, ao sofrimento e à morte, além da falta de treinamento para utilização 
das tecnologias e do relacionamento com a equipe e fatores psicossociais ${ }^{6}$.

Cabe à Psicologia reinserir a aproximação dos aspectos emocionais, conceituais e simbólicos que envolvem esse tema, buscando auxiliar no processo de cuidados de pessoas vivendo situação de perda e morte. Dessa maneira, a Psicologia contribuirá para o trabalho como educação para o processo de morrer e para a morte, envolvendo comunicação por meio de livros e recursos audiovisuais, retratando, assim, o verdadeiro sentido dessa aprendizagem para a vida nas diversas áreas que sofrem maiores influências desse processo, como a Enfermagem ${ }^{1}$.

0 processo de morrer e a morte envolvem diversos sentimentos de acordo com a situação em que cada indivíduo se encontre. 0 processo de morrer representa o adoecimento, os tratamentos e as internações hospitalares que podem significar dor e sofrimento, pela qual o maior temor é a morte. A morte é o fim, e traz a ideia do temor da finitude humana, mas pode ter o sentido de alívio em algumas situações, principalmente com a inserção de novas tecnologias e o tema de cuidados paliativos. Os trabalhadores da Enfermagem atuam nesse contexto auxiliando os pacientes e familiares nas situações de adoecimento e morte, em diversas esferas do cuidado, tanto emocional quanto assistencial, portanto devem estar bem preparados para não sofrerem no exercício do trabalho ${ }^{7-9}$.

$\mathrm{Na}$ realidade vivenciada por esses profissionais, e ainda mais pela Enfermagem, que acompanha o paciente em tempo integral, pelo fato de a Unidade de Terapia Intensiva ter os casos mais graves, a morte se torna mais frequente. Dessa forma, emerge a inquietação pela compreensão de acadêmicos de Enfermagem frente ao morrer e à morte dos pacientes sob seu cuidado. Assim, o objetivo deste estudo é investigar a percepção de estudantes de Enfermagem frente ao processo de morrer e à morte em UTIs, com análise de contribuição da Psicologia com base na abordagem feita por Kovács ${ }^{10,11}$ em estudos sobre a morte e o morrer e a necessidade de uma educação para a morte para os profissionais da saúde.

\section{MÉTODO}

Pesquisa realizada na UTI de um hospital universitário do interior de Minas Gerais, no segundo semestre de 2010, com abordagem qualitativa de caráter exploratório. $\mathrm{Na}$ pesquisa qualitativa, os pesquisadores procuraram entender os fenômenos estudados, interpretando-os segundo a perspectiva dos participantes da situação enfocada, preocupando-se com o universo dos significados, valores, crenças, reações e aspirações nas relações do homem. 0 caráter exploratório busca a identificação e descrição das características, propriedades e relações da realidade pesquisada, buscando compreender as relações existentes entre os elementos que a compõe $\mathrm{e}^{12}$.

Os critérios para inclusão dos sujeitos na pesquisa foram: estar no sétimo ou oitavo período do curso de Enfermagem, cursando os estágios supervisionados na Unidade de Terapia Intensiva, e aceitar participar da pesquisa de forma consciente e voluntária, com posterior assinatura do Termo de Consentimento Livre e Esclarecido. A pesquisa se iniciou após autorização da unidade hospitalar e da unidade de ensino, com a aprovação do Comitê de Ética em Pesquisa, respeitada, assim, a Resolução 196/96, do Conselho Nacional de Saúde ${ }^{13}$.

A coleta de dados ocorreu no segundo semestre de 2010, no momento em que o estudante realizava o estágio na UTI, após ter sido convidado a participar da pesquisa com esclarecimento de todas as informações necessárias. A entrevista individual foi realizada com auxílio de um roteiro semiestruturado, em local reservado na própria unidade, com a atribuição de um nome fictício para cada participante, de modo a garantir o sigilo e a proteção à individualidade dos sujeitos. A entrevista foi transcrita no próprio roteiro pelo pesquisador para posterior análise.

Os dados foram analisados por meio do método da Adaptação da Análise de 
Conteúdo proposta por Gomes ${ }^{14}$. Realizada com base na leitura flutuante dos dados, identificaram-se os núcleos de sentido nos discursos, sendo estes agrupados em duas categorias por semelhanças, buscando-se, assim, a interpretação detalhada dos significados.

\section{RESULTADOS}

O estágio supervisionado no hospital ocorre em forma de rodízio pela clínica médica, clínica cirúrgica, bloco cirúrgico, sala de curativo e UTI, sendo este geralmente o último setor de estágio, para melhor aproveitamento e desenvolvimento das atividades. Participaram da pesquisa 12 discentes que estavam em estágio supervisionado na UTI e que desenvolviam atividades voltadas para o domínio dessa área específica de atuação. 0 setor era composto por cinco leitos, com pacientes geralmente idosos, com complicações clínicas graves e longos períodos de internação. 0 estágio obrigatório na área hospitalar totalizava 300 horas a serem realizadas em um semestre, dividas pelos diversos setores do hospital, com plantões de $6 \mathrm{~h}$ em dias estipulados na semana, com a possibilidade de realização de alguns plantões noturnos de $12 \mathrm{~h}$ cada.

Dentre as experiências hospitalares que os entrevistados possuíam anteriormente, podem-se identificar três tipos de alunos: aqueles com experiência exclusiva do curso de graduação em Enfermagem (clínica médica, clínica cirúrgica, bloco cirúrgico e UTI); outros que, além desta, realizaram estágios voluntários em hospitais; e aqueles que, além das experiências oferecidas pelo curso, já possuíam formação profissional na área da saúde (superior ou técnica), alguns desses exercendo atividades hospitalares no momento do curso. Para melhor análise das entrevistas, os dados foram divididos em duas categorias: Concepção Prévia e Contextualização da Situação.

\section{- Concepção prévia}

A concepção prévia representa o conhecimento inicial do estudante, suas expectativas e valores ao vivenciar o ingresso no estágio. Podem-se identificar os seguintes núcleos de sentido: Expectativa de Ingresso no Estágio, Valores Pessoais, Conhecimento sobre o Tema no Início do Estágio.

Na Expectativa de Ingresso no Estágio, identificaram-se vários tipos de sentimento: ansiedade, medo de lidar com o sofrimento do outro e pensamentos confusos sobre a morte. Mas alguns também apresentaram sentimentos positivos, como a ideia de que o estágio era uma experiência nova de muita aprendizagem, com necessidade de compreensão, de prestação de cuidado humanizado e efetivo no ambiente hospitalar. As falas a seguir ilustram esse núcleo de sentido:

- Tenho medo de lidar com o sofrimento do outro (Arnaldo);

- Será de grande aprendizagem a realização do estágio nessa unidade (Bruna);

- Sinto um sentimento confuso, atribulado com a rotina, pensamento de morte, sinto que pode ser traumatizante (Carlos);

- Tenho medo de realizar alguma atitude que piorasse ainda mais a situação dos pacientes, $o$ ambiente apresenta ser muito complexo (Júlio);

- Tenho muita ansiedade e receio de não conseguir realizar as atividades (Herick).

No que se refere ao relacionamento com os profissionais da UTI, os entrevistados apresentaram a expectativa de respeito ao próximo, prevalecendo a amizade, a alegria e o entusiasmo. Em relação aos pacientes houve poucas expectativas, já que o estado clínico destes dificultava o diálogo, pois geralmente estavam sedados. Apontaram que o local precisava de atenção humanizada, tanto em relação ao paciente quanto no que se referia à equipe.

No núcleo de sentido Valores Pessoais dos entrevistados referentes à morte, esta foi vista como uma fase, uma passagem para outra vida, fim do estágio na terra. Outros a viam como uma evolução natural, única certeza da vida, devendo ser encarada com naturalidade. Outros ainda associavam a morte a algo temido, revelando sentimentos de negação, dor e sofrimento, não só no 
tocante à própria morte como com relação à de seus familiares e pacientes. Alguns, mesmo demonstrando sentimento de medo, entendiam que deveriam ter capacidade para lidar com a situação como futuros enfermeiros:

- Percebo que a morte é uma fase, uma passagem, a única certeza da vida (Arnaldo);

- Vejo que com ela se cumpre, acaba o estágio na terra, não vejo como fim, acredito na continuação da vida (Bruna);

- Tenho medo da morte, tanto para mim, meus pacientes e familiares (Eni);

- Acho que é normal, faz parte da vida (Daniele);

- No início parecia ser triste, mas percebo que em certas ocasiões vem como alívio do sofrimento de todos (Júlio);

- Acho que é a única certeza que todos os seres humanos têm, mas temos que encará-la com naturalidade e maturidade (Mariana).

Em relação ao Conhecimento sobre o Tema no Início do Estágio, verificou-se que os entrevistados não receberam suporte teórico anterior - os estágios acabavam sendo a única possibilidade de abordagem do tema. Os acadêmicos que expressaram melhores condições de lidar com esse assunto referiram terem tido experiências anteriores por meio de vivência pessoal e profissional.

Quase todos os entrevistados relataram que não tiveram nenhuma disciplina que abordasse a questão de como lidar com a morte no decorrer do curso de Enfermagem. Os que revelaram terem realizado discussão sobre o tema informaram que esta se deu pela troca de experiências com os profissionais durante os estágios, de forma aleatória, não abrangendo todos os estudantes, como verificado nas falas a seguir:

- Não estudei sobre o tema, aprendi através da troca de experiência com os profissionais da saúde e com as experiências da minha própria vida (Arnaldo);

- Não tive contato com o tema, me considero ser uma pessoa muito emotiva, com dificuldades e o curso não contribuiu, nem com parte teórica e nem na prática (Bruna);
- Não tive contato teórico com o tema, minha segurança foi diante de minhas vivências, o curso contribuiu com os estágios, abrindo a possibilidade de presenciar o óbito (Carlos);

- Não estudei o assunto, sinto que minha preparação foi diante dos estágios anteriores, como voluntária e prestando assistência, lidando bem com a morte, o curso não ofereceu nenhuma parte teórica, mas proporciona os estágios dando oportunidade para essas ocasiões (Daniele).

Sobre o preparo para lidar com a morte dos pacientes, observou-se que, apesar do curso de Enfermagem não ter oferecido subsídios necessários para a discussão do tema, alguns estudantes se sentiam preparados para lidar com a morte de seus pacientes. Isso se explica em virtude do perfil que os entrevistados apresentaram, tendo uma vez que, vários discentes que já possuíam alguma profissão na área da saúde e outros que fizeram estágios voluntários. Pode-se perceber, nas falas a seguir, o preparo para vivenciar a morte:

- Sinto-me preparado, mas depende do caso, pois a morte para alguns é a única alternativa (Arnaldo);

- Percebo que é um acontecimento que faz parte da vida e terei que lidar muito, penso que será difícil no começo, mas que vou superar (Bruna);

- Estou preparada para vivenciar a morte nos estágios, pois não me envolvo sentimentalmente com o paciente, pois se ultrapassar os limites se tornaria um paciente (Daniele);

- Não estou preparada para isso, tenho dificuldades em lidar com a morte, medo das perdas, quando se cria vínculo a dificuldade aumenta (Eni);

- Não me sinto preparado, mas pretendo lidar bem com a situação (Flávio).

\section{- Contextualização da situação}

A contextualização da situação significa entender a dinâmica da unidade no ingresso dos estudantes, o contexto que ocorre ao vivenciarem a morte e o processo de morrer, bem como os fatores envolvidos. Sendo a UTI um ambiente fechado, complexo, com alta tecnologia e pacientes graves, há alto índice de mortalidade em relação a outros setores 
do hospital. Nessa categoria identificaram-se os seguintes núcleos de sentido: Experiência dos Estudantes no Início do Estágio e Processo de Reflexão.

Em relação à Experiência dos Estudantes no Início do Estágio, dentre os entrevistados durante o primeiro momento do estágio supervisionado na UTI, apenas os que já haviam tido contato com o setor e conheciam os profissionais apresentaram tranquilidade e segurança ao ingressar no estágio. Os demais alunos, mesmo os que já possuíam formação em outra área da saúde, apresentaram ansiedade e medo em relação à realidade da unidade. Pode-se verificar tal fato nas seguintes falas:

- Achei o relacionamento difícil devido ao estado do paciente, os profissionais são receptivos (Carlos);

- Senti a equipe fechada, sem problemas na parte técnica e emocional (Gisele);

- Tive medo e insegurança, tentei atuar com uma preocupação em não atrapalhar a dinâmica do serviço, senti insegurança em conversar com os familiares, medo de dizer informações que não podem ser passadas (Júlio).

Durante a realização das atividades no decorrer do estágio, os discentes percebiam que a UTI, apesar de ser um setor complexo, apresentava períodos de tranquilidade, não representando as ideias que os alunos possuíam do setor antes desse contato:

- Pensava que todos os pacientes apresentavam parada cardiorrespiratória a toda hora, mas constatei que não é assim, apesar de ser um ambiente complexo, com muita aparelhagem, aparenta ser tranquilo (Bruna).

Entre os doze sujeitos da pesquisa, oito presenciaram o óbito de pacientes sob seu cuidado. Decorrente disso, diversos sentimentos foram verificados: alguns apresentaram alívio diante do sofrimento do quadro do paciente, seriedade, respeito e empatia com os familiares no momento de sua dor; outros sentiram-se assustados e demonstraram piedade. Dentre os que não vivenciaram o óbito de seus pacientes, todos acreditavam que se abalariam, e alguns relataram que ficariam tristes e chateados com a notícia do óbito de pacientes que tivessem assistindo. A vivência do óbito é percebida nas falas a seguir:

- Não fiquei angustiado quando vivenciei a morte, não era ninguém da minha família, me sinto forte para lidar com o óbito do pacientes, se envolvendo apenas para prestar assistência (Arnaldo);

- Fiquei muito nervoso, com vontade de chorar, colocando-se no lugar da família (Flávio).

O Processo de Reflexão busca uma reformulação dos conceitos prévios e adquiridos durante o contato com a realidade do estágio pelos estudantes. Nas entrevistas, perguntou-se para os acadêmicos o que eles achavam que o curso poderia fazer para ajudar a lidar com a vivência da morte de seus pacientes. Alguns depoimentos se destacam:

- Na parte teórica, necessita de uma abordagem com um olhar da Psicologia, muitas pessoas não conseguem separar a vida pessoal da profissional, o curso precisa disponibilizar isso, pois tem pessoas que choram levando para a casa essas angústias (Carlos);

- Poderia ter aulas com professores preparados sobre tanatologia, fazendo uma ligação com a religião, preparando o aluno $e$ inseri-lo no estágio desde o começo do curso (Gisele);

- Seria importante oferecerem um preparo psicológico, talvez se necessário uma psicoterapia individual, trabalhar esta questão com mais ênfase, principalmente no último período, onde ele aparenta ser mais necessário para subsídio dos alunos (Herick).

A abordagem teórica para confrontar os valores e as experiências dos acadêmicos possibilita reflexões sobre as questões que envolvem o processo de morrer e a morte. As atividades durante os estágios supervisionados na UTI servem como estreitamento entre teoria e prática, para que os discentes tenham subsídios necessários para a realização das atividades referentes à sua futura profissão. 


\section{DISCUSSÃO}

0 estudo em questão mostrou que os alunos se sentem ansiosos, com medo, com dificuldades de lidar com o sofrimento do outro no ambiente de UTI, convivendo com pessoas em estado grave e por vezes em processo de morrer e em risco de morte. Ao mesmo tempo, os acadêmicos de Enfermagem entendem ser a morte um processo natural, mas não se sentem preparados, e ainda referem não receber suporte teórico para compreender, lidar com e enfrentar a morte do indivíduo sob seus cuidados. Evidenciam ainda a necessidade de reformulação do ensino teórico no tocante ao tema processo de morrer e morte.

A postura de um indivíduo perante a morte em cada sociedade pode ter desdobramentos culturais diversos que precisam ser compreendidos e interferem em como a pessoa se comporta em relação à morte. É necessário refletir sobre certos valores cultivados ao longo da vida e que podem ajudar ou dificultar a aceitação da morte. Os indivíduos passam a reavaliar seus próprios valores e crenças na tentativa de uma construção mais sólida dessas questões ${ }^{10,11}$.

Um graduando de Enfermagem pode às vezes não se dar conta de que a sua responsabilidade no cuidar está em todos os ciclos da vida, incluída aí a morte.

A Tanatologia, ciência interdisciplinar que tem como foco o estudo da mortemorrer, é adotada pelo Núcleo Interdisciplinar de Pesquisa em Perdas e Luto da Escola de Enfermagem da Universidade de São Paulo, e tem como objetivo contribuir com o esclarecimento com base nos relatos apresentados sobre a morte. Esse espaço permite a discussão sobre o tema nos mais diversos contextos de assistência à saúde, de modo a ajudar a dignificar e humanizar essa etapa ${ }^{15}$. Com esse intuito, acredita-se que a compreensão sobre a morte possa proporcionar um significado aos estudantes de Enfermagem, atribuindo ao termo morte conceitos básicos e utilizando diferentes teorias no lidar com o final da vida. A assistência aos pacientes durante o processo morte-morrer mudou nos últimos anos, e o grande avanço da Tanatologia em curto espaço de tempo provocou, entre a teoria e a prática, uma lacuna que necessita ser preenchida $10,11,15$.

Ter um espaço para reflexão não tira a responsabilidade da instituição de ensino de dar fundamentação sobre o processo de morrer e a morte ${ }^{10,11}$. Em estudo sobre o preparo dos acadêmicos de Enfermagem brasileiros para vivenciarem o processo morte-morrer, os discentes propuseram incluir o tema na grade curricular, estabelecendo espaço para a troca de experiências entre professores e alunos acerca das questões que o tema envolve, a construção de grupos para debates desses assuntos, a abordagem psicológica no que se refere a esse processo, a realização de cursos, seminários e demonstrações de como agir na situação de morte do paciente e a abordagem da família ${ }^{16}$.

Em pesquisa realizada por Benincá17 com auxiliares de Enfermagem de uma UTI sobre o processo de morrer e morte dos pacientes, utilizou-se a intervenção coletiva com uso de grupo de apoio como estratégia de reflexão para esses trabalhadores. Buscou-se descrever a unidade por meio da observação e de entrevistas e do levantamento de temas em grupos de discussão. Nesse ambiente, os auxiliares de Enfermagem puderam perceber a representação do seu papel no setor como uma das estratégias de apoio psicológico, além de refletirem sobre suas experiências, compreendendo melhor o sentimento de adoecer e a morte, levando, portanto, ao desenvolvimento de indivíduos com preservação da saúde mental.

Os cursos de Enfermagem no Brasil têm, nas últimas décadas, incorporado disciplinas que podem dar aporte à compreensão do processo de morrer e da morte. A exemplo, a inclusão das disciplinas Psicologia, Antropologia, entre outras ${ }^{18}$.

A simples inclusão de disciplinas também não garante que temáticas de interesse para a formação do enfermeiro ocorram. A coordenação de um curso de graduação em Enfermagem precisa 
redirecionar os professores, em especial aqueles que não sejam do tronco profissionalizante.

A disciplina Psicologia não pode abrir mão do tema processo de morrer e morte na graduação em Enfermagem, pois tal temática pode preparar o aluno para o momento de estágio e, mais do que isso, para a vida profissional. A discussão sociocultural do processo de morrer e da morte pode ser um tópico a ser discutido em Antropologia, que em muitas faculdades de Enfermagem chama-se Antropologia Filosófica. A disciplina Ética e/ou Bioética deve ser um espaço de reflexão sobre o respeito ao estar morrendo e à família, ao cuidado com o corpo, à dignidade humana e ainda, às questões legais ${ }^{19,20}$.

De fato, o mundo ocidental tem um olhar sobre a morte que não se compara ao do mundo oriental que, mesmo com o sofrimento da perda, tem vias de enfrentamento diferenciadas, o que repercute também na formação em saúde, que depende das dinâmicas culturais nas quais as pessoas estão envolvidas ${ }^{20}$.

Cabe ainda ressaltar que, por mais preparado que esteja teoricamente para aceitar a morte, no primeiro óbito que vá assistir, o acadêmico de Enfermagem pode sofrer muito. Nesse ponto, parece importante ressaltar a relevância da atuação do psicólogo, tanto na formação de profissionais de saúde para o enfrentamento de temas complexos, como o processo de morrer e a morte, quanto na sua atuação no hospital, em especial em clínicas com a complexidade de uma UTI.

A própria instituição de ensino pode oferecer orientação e apoio por meio da ação de um psicólogo a alunos da área de saúde. Além disso, a atuação do psicólogo hospitalar é imprescindível no apoio às famílias e aos profissionais de saúde. No momento da inserção de "aprendizes do cuidado" - futuros enfermeiros, o psicólogo também pode atuar no favorecimento da compreensão da dinâmica de uma UTI e do processo de morrer e da morte. 0 psicólogo, como integrante da equipe de saúde, deve ajudar na construção de suportes para lidar com o fenômeno da morte.

Pensando nesse adequado suporte estrutural, foi proposta pela primeira vez a disciplina "Psicologia da Morte", no Instituto de Psicologia da USP, em 1986, como matéria optativa para os estudantes de Psicologia que queriam realizar uma maior abordagem desse tema. Isso se deu após a dissertação de mestrado defendida por Kovács, em 1985, intitulada "Um estudo sobre o medo da morte em estudantes universitários das áreas de saúde, humanas e exatas". Essa disciplina aborda a aprendizagem significativa, e considera três questões básicas: a teoria, a prática e o desenvolvimento pessoal, na tentativa de oferecer um questionamento da teoria e dos valores do aluno ${ }^{10,11 .}$

A troca de experiências entre um profissional e outro, ou entre um profissional e um aluno frente ao óbito dos pacientes sob seus cuidados, já proporcionaria um alívio para todos, uma vez que essa questão não é nenhuma particularidade, representando, assim, uma dificuldade que todos na área da saúde acabam enfrentando, alguns mais que outros, dependendo da situação de trabalho.

Além de fundamentação teórica, deve ser proporcionado um espaço de troca de experiências para melhor reflexão. Os acadêmicos de Enfermagem, ao iniciarem os estágios supervisionados, passarão pela experiência próxima da finitude humana. É preciso que estejam preparados para a experiência da morte de seus pacientes, independentemente da idade, pois, quando não elaborado esse processo, torna-se mais difícil a realização das atividades no decorrer do estágio supervisionado em locais onde sua presença é constante. Estudar a morte-morrer no contexto da formação do enfermeiro contribui para a humanização do processo educativo e a formação profissional crítica e humanista ${ }^{21}$.

\section{CONCLUSÃO}

Ao investigar a percepção dos acadêmicos de Enfermagem frente ao processo de morrer e à morte, com análise de contribuição da 
Psicologia, verificou-se a necessidade da revisão dos conteúdos teóricos incluídos na formação do enfermeiro com relação ao tema, bem como a necessidade da atuação do psicólogo, tanto no ambiente acadêmico quanto na instituição assistencial.

A Psicologia, como ciência que estuda os processos mentais e o comportamento humano abordando a subjetividade, deve contribuir na formação das diversas profissões de saúde, especialmente no caso da Enfermagem, que lida por tempos prolongados com pacientes críticos.

Tendo em vista a necessidade de uma melhor compreensão da morte pelos estudantes de Enfermagem, sugere-se a realização de oficinas, dinâmicas, palestras, aulas, encontros entre alunos e profissionais, o que pode proporcionar a construção de um espaço para reflexão e compreensão e facilitar o melhor enfrentamento de situações complexas de ensinoaprendizagem, como o processo de morrer e a morte.

Sem a ambição de generalizações fora do escopo de uma pesquisa qualitativa, pode-se inferir que esta seja a realidade de várias faculdades de Enfermagem, o que mereceria um mapeamento mais amplo a respeito, o que foge ao âmbito deste estudo, embora seja necessária a compreensão do fenômeno.

Por sua vez, parece importante destacar que a área de Psicologia deve estar atenta à necessidade de sua inserção na formação dos profissionais de saúde, bem como à sua necessária contribuição para a compreensão de fenômenos de difícil enfrentamento individual e social, e isso não só para a aprendizagem clínica, mas também para a atuação profissional, sendo o processo de morrer e a morte um dos temas importantes, mas possivelmente não o único.

\section{REFERÊNCIAS}

1. Combinato DS, Queiroz M. Morte: uma visão psicossocial. Estud. Psicol. (Natal). 2006; 11(2):209-16.

2. Oliveira WIA, Amorin RC. A morte e o morrer no processo de formação do enfermeiro. Rev. Gaúcha de Enferm. 2008; 29(2):191-8.
3. Rodrigues JC. Higiene e ilusão. Rio de Janeiro: NAU; 1995.

4. Elias N. A solidão dos moribundos, seguido de envelhecer e morrer. Rio de Janeiro: Jorge Zahar; 2001.

5. Bellato R, Araújo AP, Ferreira HF, Rodrigues PF. Abordagem do processo do morrer e da morte feita por docentes em um curso de graduação em Enfermagem. Acta Paul. Enferm. 2007; 20(3):25563.

6. Rezende T, Silva RM. A qualidade de vida no trabalho dos profissionais da área de Enfermagem: um estudo a partir do modelo teórico de Hackman \& Oldham. Estud. Pesq. Psicol. 2008;8(3):685-703.

7. Borges ADVS, Silva EF, Toniollo PB, Mazer SM, Valle ERM, Santos MA. Percepção da morte pelo paciente oncológico ao longo do desenvolvimento. Psicol. Estud. 2006; 11(2):361-9.

8. Oliveira JBA, Lopes RGC. O processo de luto no idoso pela morte de cônjuge e filho. Psicol. Estud. 2008; 13(2):217-21.

9. Oliveira EA, Santos MA, Mastropietro AP. Apoio psicológico na terminalidade: ensinamentos para a vida. Psicol. Estud. 2010;15(2):235-44.

10. Kovács MJ. Desenvolvimento da tanatologia: estudos sobre a morte e o morrer. Paidéia (Ribeirão Preto). 2008; 18(41):457-68.

11. Kovács MJ. Educação para morte: desafio na formação de profissionais de saúde e educação. São Paulo: Casa do Psicólogo; 2003.

12. Minayo MCS. Pesquisa social: teoria, método e criatividade. Petrópolis: Vozes; 2000.

13. Ministério da Saúde (Br). Resolução no 196, de 10 de outubro de 1996. Aprova diretrizes e normas regulamentadoras de pesquisas envolvendo seres humanos. D.O.U, Brasília, DF, n. 201, 1996 out 16. Seção 1, p. 21082-5.

14. Gomes R. Análise e interpretação de dados de pesquisa qualitativa. In: Minayo MCS, Deslandes SF, Gomes R., organizadores. Pesquisa social: teoria, método e criatividade. Petrópolis: Vozes; 2007. p. 79-108.

15. Bousso RS, Poles K, Rossato LM. Desenvolvimento de conceitos: novas direções para a pesquisa em tanatologia e enfermagem. Rev. Esc. Enferm. USP. 2009; 43(Esp2):1331-6.

16. Bernieri J, Hirdes A. O preparo dos acadêmicos de enfermagem brasileiros para vivenciarem o processo morte-morrer. Texto e Contexto enferm. 2007; 16(1):89-96.

17. Benincá CRS. Apoio psicológico à enfermagem diante da morte: estudo fenomenológico. [tese]. Porto Alegre: Universidade Federal do Rio Grande do Sul, Instituto de Psicologia; 2002.

18. Esquerdo FA, Pegoraro RF. Contribuições da 
Psicologia para a formação do técnico em Enfermagem: concepções dos alunos. Psicol. Estud. 2010; 15(2):255-64.

19. Bretas JRS, Oliveira JR, Yamaguti L. Reflexões de estudantes de Enfermagem sobre morte e o morrer. Rev. Esc. Enferm. USP. 2006; 40(4):477-83.

20. Menezes RA. Em busca da boa morte: Antropologia dos cuidados paliativos. Rio de Janeiro: Fiocruz; 2004.

21. Pinho LMO, Barbosa MA. A relação docenteacadêmico no enfrentamento do morrer. Rev. Esc. Enferm. USP. 2010; 44(1):107-12.

\section{CONTRIBUIÇÕES}

Gheysa Alves Mendonça participou na concepção, delineamento, análise e interpretação dos dados e redação;

Valtuir Duarte Souza Júnior atuou na concepção, delineamento, análise e interpretação dos dados e na redação;

Nivea Lourenço Santos Correio relacionou-se com a concepção, delineamento, análise interpretação dos dados;

Álvaro da Silva Santos participou na análise e interpretação dos dados, redação e revisão crítica. 